\title{
Review
}

\section{Mitochondrial complex III regulates hypoxic activation of HIF}

\author{
T Klimova ${ }^{1,2}$ and NS Chandel ${ }^{*, 1,2}$
}

Decreases in oxygen levels are observed in physiological processes, such as development, and pathological situations, such as tumorigenesis and ischemia. In the complete absence of oxygen (anoxia), mammalian cells are unable to generate sufficient energy for survival, so a mechanism for sensing a decrease in the oxygen level (hypoxia) before it reaches a critical point is crucial for the survival of the organism. In response to decreased oxygen levels, cells activate the transcription factors hypoxiainducible factors (HIFs), which lead to metabolic adaptation to hypoxia, as well as to generate new vasculature to increase oxygen supply. How cells sense decreases in oxygen levels to regulate HIF activation has been hotly debated. Emerging evidence indicates that reactive oxygen species (ROS) generated by mitochondrial complex III are required for hypoxic activation of HIF. This review examines the current knowledge about the role of mitochondrial ROS in HIF activation, as well as implications of ROS-level regulation in pathological processes such as cancer.

Cell Death and Differentiation (2008) 15, 660-666; doi:10.1038/sj.cdd.4402307; published online 25 January 2008

\section{Oxygen Homeostasis and HIF}

Maintaining oxygen homeostasis is critical for survival and proper function of cells and organisms. ${ }^{1}$ Reduced oxygen levels (hypoxia) initiates proper placental and vascular development. Hypoxia also has a causal role in pathological conditions such as ischemia-related diseases and cancer. A complete absence of oxygen (anoxia) results in cell death. ${ }^{2}$ ATP synthesis is ablated, and most cells undergo apoptosis soon after anoxia exposure..$^{3-5}$ Cells exposed to hypoxia, or reduced oxygen levels, on the other hand, are able to maintain normal ATP synthesis and survive. ${ }^{5,6}$ However, as cells replicate in a hypoxic environment, they reduce the oxygen supply even further and generate levels of local anoxia. Therefore, cells must respond quickly to decreasing oxygen levels before reaching an anoxic state (Figure 1).

Mammalian cells respond to hypoxia by activating broadaction transcription factors named hypoxia-inducible factors, or HIFs, which are expressed by virtually all cells of the body. ${ }^{7-9}$ Three members of the HIF family exist, named HIF1, HIF2 and HIF-3. ${ }^{10-13}$ HIFs bind to hypoxia-responsive elements, consensus sequences in the promoter region of more than one hundred genes, activating the transcription of genes that allow the cell to adapt to and survive in the hypoxic environment. ${ }^{14,15}$ Genes regulated by HIFs include glucose transporter that allow the cells to efficiently import glucose to continue generating ATP despite reduced nutrient availability; and genes that reorganize the microenvironment to bring in oxygen, such as vascular endothelial growth factor, which stimulates formation of new blood vessels. ${ }^{16-18}$ Importantly for tumorigenesis, HIF also turns on genes such as insulin-like growth factor ${ }^{2,19}$ which induces cellular survival and proliferation, as well as those that promote tumor invasion and migration, such as matrix metalloproteinase- $2 .{ }^{20}$ These factors contribute to tumor growth and invasion and metastasis, implicating HIFs as important protumorigenic factors.

\section{Regulation of HIF Function}

HIF is a heterodimer, consisting of a constitutively stable HIF $\beta$ subunit (also known as aryl hydrocarbon translocator, or ARNT) and an oxygen-sensitive HIF $\alpha$ subunit. ${ }^{21-23}$ HIF $\alpha$ and HIF $\beta$ are continuously transcribed and translated. However, under normal oxygen conditions (normoxia; defined here as $21 \% \mathrm{O}_{2}$ ), the $\mathrm{HIF} \alpha$ subunit is hydroxylated at conserved proline residues in the oxygen-dependent degradation domain by prolyl hydroxylate enzymes (PHDs) (Figure 2). ${ }^{24-25}$ In addition to oxygen, the PHDs require iron and 2-oxoglutarate as substrates for hydroxylation. ${ }^{26}$ Indeed, the hydroxylation of the HIF $\alpha$ protein can be inhibited by iron chelators or with dimethyloxallyl glycine, a competitive inhibitor with respect to 2 -oxoglutarate. ${ }^{27}$ The hydroxylated proline residues of the HIF $\alpha$ protein are then recognized by an E3 ubiquitin ligase, von Hippel-Lindau protein (pVHL), which subsequently targets HIF for rapid degradation by the proteasome. ${ }^{28-30}$ An inherited deficiency in pVHL allows HIF to become constitutively active, leading to renal cell carcinoma, further illustrating the importance of HIF in cancer pathology. ${ }^{31,32}$

\footnotetext{
${ }^{1}$ Department of Medicine, Northwestern University Medical School, Chicago, IL 60611, USA and ${ }^{2}$ Department of Cell and Molecular Biology, Northwestern University Medical School, Chicago, IL 60611, USA

${ }^{*}$ Corresponding author: NS Chandel, Department of Medicine, Northwestern University Medical School, McGaw Pavillion, 240 East Huron Avenue M-334, Chicago, IL 60611, USA. Tel: + 312503 2549; Fax: + 312908 8163; E-mail: nav@northwestern.edu

Keywords: HIF; hypoxia; mitochondria; complex III; ROS

Abbreviations: COX, cytochrome $c$ oxidase; DFO, desferrioxamine; FIH, factor-inhibiting HIF; HIF, hypoxia-inducible factor; NAC, N-acetylcysteine; PHDs, prolyl hydroxylases; pVHL, von Hippel-Lindau; Q, ubiquinone; QH2, ubiquinol; ROS, reactive oxygen species

Received 16.10.07; revised 27.11.07; accepted 30.11.07; Edited by RA Knight; published online 25.1.08
} 

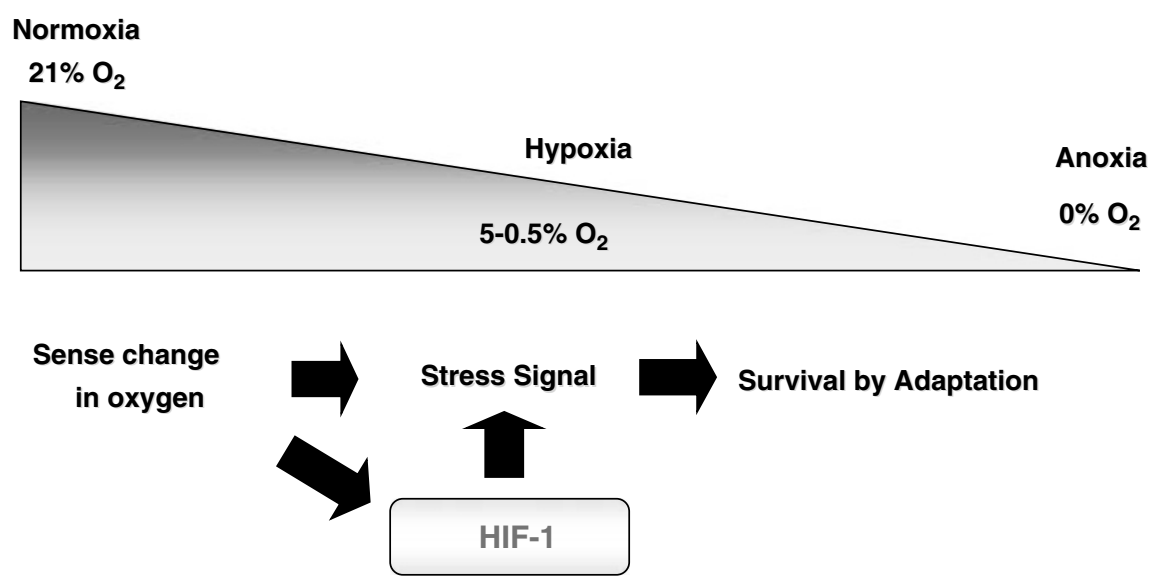

Figure 1 Mammalian cells respond to decreases in oxygen levels by activating a stress signal response, which triggers hypoxia inducible factors 1 and/or 2 for adaptation and subsequent survival

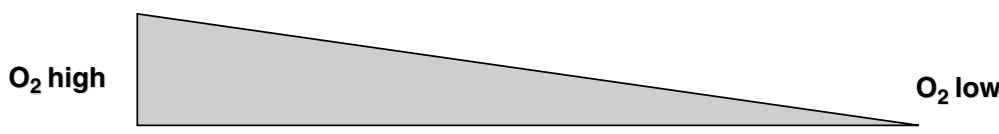

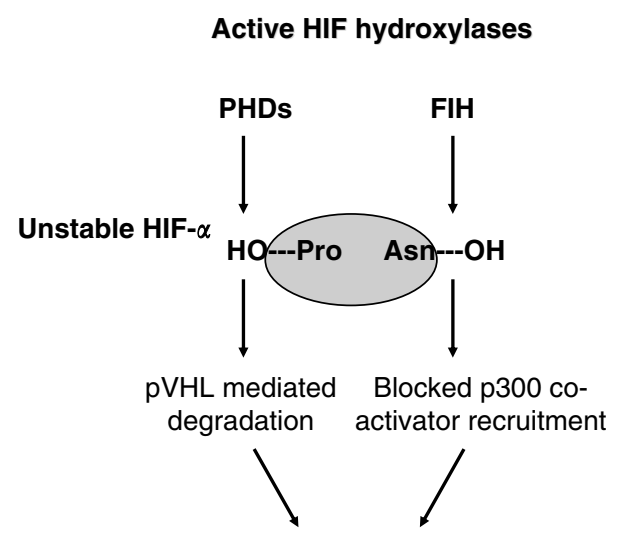

Inactivation of HIF transcriptional activity
Inactive HIF hydroxylases

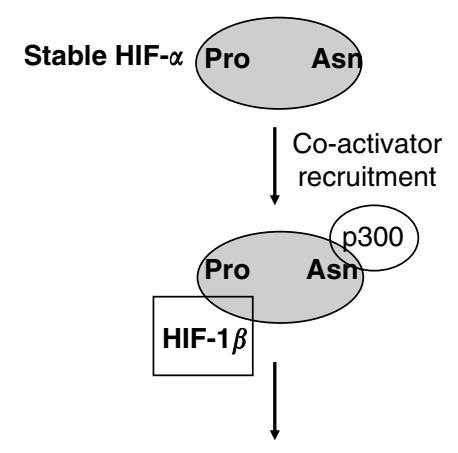

Activation of HIF transcriptional activity

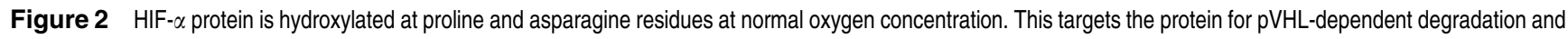
prevents binding to transcriptional coactivators such as $\mathrm{p} 300$. As cells become hypoxic, hydroxylation of HIF- $\alpha$ protein is prevented, resulting in stabilization of the protein and binding to $p 300$ to activate its transcriptional activity

HIF is additionally hydroxylated at an asparagine residue by factor-inhibiting HIF $(\mathrm{FIH}) .{ }^{33-35}$ This prevents HIF from interacting with the transcriptional coactivators p300 and CREB-binding protein (CBP), thereby reducing the transactivating activity of HIF. ${ }^{36,37}$ Under hypoxia, however, HIF $\alpha$ is not hydroxylated by either PHDs or FIH. The lack of prolyl hydroxylation prevents pVHL from recognizing HIF $\alpha$ and targeting it for proteasomal degradation. HIF $\alpha$ can then migrate to the nucleus, dimerize with $\operatorname{HIF} \beta$, and bind specific hypoxia response elements in the promoter regions of its target genes. The absence of asparagine hydroxylation allows the HIF dimer to interact with transcriptional coactivators and initiate transcription.

PHDs as integral members of oxygen-sensing machinery. The mechanism by which cells sense hypoxia and signal for HIF- $\alpha$ protein stabilization is not fully resolved.
The original and simplest model of oxygen-sensing places PHDs as the direct sensors of oxygen levels. As previously mentioned, PHDs require oxygen for function. A logical extension is that, as oxygen availability decreases to hypoxic levels, PHDs are deprived of this crucial cofactor and become unable to hydroxylate HIF. As a result, the HIF- $\alpha$ protein is not recognized by $\mathrm{pVHL}$ and is not degraded. However, although elegantly simple, this model may not by itself explain the oxygen-dependent stabilization of the HIF $-\alpha$ protein. HIF- $1 \alpha$ protein stabilization increases in an exponential fashion as oxygen levels decrease to anoxia. ${ }^{38}$ By contrast, the PHD activity decreases in a linear fashion as oxygen levels decrease to anoxia. ${ }^{39}$ Clearly, once cells approach anoxia, the PHDs are the direct sensors for stabilization of the HIF- $1 \alpha$ protein since oxygen becomes a limiting substrate for hydroxylation. Moreover, the rate of 
hydroxylation of HIF- $\alpha$ protein is likely dependent on the required cofactors iron and 2-oxoglutarate. Thus an integrated oxygen-sensing model that accounts for the availability of oxygen and other cofactors is likely required to explain HIF-1 $\alpha$ protein stabilization over the hypoxic range.

\section{Mitochondria as integral members of oxygen-sensing} machinery. Although the PHDs are the proximal regulators of HIF- $\alpha$ protein stabilization, much evidence has emerged to suggest that the mitochondrial electron transport chain is involved in oxygen sensing and would therefore need to respond to changes in oxygen levels. This idea has long been proposed, since the electron transport chain consumes most of the cell's oxygen. The electron transport chain, which is embedded in the inner membrane of the mitochondria, consists of five multiprotein complexes. Complexes I and II oxidize the energy-rich molecules NADH and FADH2, respectively, and transfer the resulting electrons to ubiquinol, which carries it to complex III. Complex III, in turn, shuttles the electrons across the inner mitochondrial membrane to cytochrome $c$, which carries them to complex IV. Complex IV uses the electrons to reduce oxygen to water. Each electron-ferrying step uses the resulting energy to pump hydrogen ions into the intermembrane space. This generates a proton gradient, the dissipation of which is used by complex V, or ATPase, to power the energy-costly phosphorylation of ADP to ATP. Along with carrying electrons, complexes I, II, and III generate reactive oxygen species (ROS), namely superoxide, at low levels. ${ }^{40}$

Initial studies implicating the electron transport chain in HIF- $1 \alpha$ stabilization have demonstrated that certain inhibitors of the electron transport chain, including rotenone (which inhibits complex I distally), myxothiazol, and stigmatellin (which inhibit complex III) block the hypoxic stabilization of HIF-1 $\alpha .{ }^{41-43}$ Genetic deletions of complex I, likewise, blocked HIF- $1 \alpha$ stabilization. ${ }^{44}$ Finally, cells depleted of their mitochondrial DNA by incubation with low levels of ethidium bromide (known as rho-zero cells) fail to stabilize HIF-1 $\alpha$ in response to hypoxia. ${ }^{43}$ While mitochondrial DNA encodes only 13 genes, these are crucial components of complexes I, III, IV, and V, and cells lacking these components do not have a functional electron transport chain. ${ }^{45}$ These cells, however, are still capable of stabilizing HIF-1 $\alpha$ protein when exposed to hypoxia mimetics, such as the iron chelator DFO, demonstrating that HIF- $1 \alpha$ protein stabilization per se is intact. ${ }^{41,43}$ Together, these initial results suggest that hypoxic stabilization of HIF- $1 \alpha$ requires a functional electron transport chain, though they did not show specifically the oxygen-sensing site, nor explained how loss of electron transport may stabilize HIF- $1 \alpha$.

The findings that a functional electron transport chain is required for hypoxic stabilization of $\mathrm{HIF} \alpha$ protein fell under scrutiny, specifically from contradictory reports. In one of these studies, rho-zero cells were shown to be capable of stabilizing HIF-1 $\alpha$ under hypoxia. ${ }^{46}$ However, these studies utilized oxygen levels very close to anoxia $(0.1 \%)$, rather than true hypoxia $\left(1-2 \% \mathrm{O}_{2}\right)$. Anoxia, like hypoxia, stabilizes the HIF-1 $\alpha$ protein. However, the mechanisms employed by anoxia appear quite different. These differences are explored in a study by Schroedl et al., ${ }^{5}$ which shows that rho-zero cells are, indeed, capable of stabilizing HIF-1 $\alpha$ protein under anoxia, but not under hypoxia (defined in that study as $1.5 \%$ $\mathrm{O}_{2}$ ). Anoxic cells, unlike hypoxic cells, experience a significant drop in oxygen consumption and ATP production, and die within $48 \mathrm{~h}$, while hypoxic cells continue to survive and multiply. This study highlighted the differences between anoxia and hypoxia. Since oxygen is entirely limited in anoxia, it is likely that anoxic cells stabilize HIF-1 $\alpha$ protein through impaired PHD function.

An alternative explanation for the contradictory results from rho-zero cells is the use of ethidium bromide, a potential mutagen, to generate these cells. To resolve these discrepancies, three independent groups utilized the power of genetics to conclusively demonstrate that mitochondrial electron transport chain is required for hypoxic stabilization of HIF- $1 \alpha$ protein. The first study by Celeste Simon's group demonstrated that cells lacking cytochrome $c$ fail to stabilize the HIF-1 $\alpha$ protein in hypoxia. ${ }^{47}$ The other two studies done by Paul Schumacker's group and ours demonstrated that RNAi of the Rieske-Fe-S protein, a complex III subunit, prevents hypoxic stabilization of HIF- $1 \alpha$ protein. ${ }^{48,49}$ Collectively, these studies provided conclusive genetic evidence that mitochondrial electron transport chain is required for $\mathrm{HIF}-1 \alpha$ protein stabilization.

The observation that genetic or pharmacologic inhibition of mitochondrial electron transport chain prevents hypoxic stabilization of HIF- $\alpha$ protein begs the question: which function of the electron transport chain is necessary for HIF- $\alpha$ protein stabilization? Two main theories have arisen to address this question. The first theory suggests that, under hypoxia, mitochondria, with their high oxygen consumption, leave the rest of the cell 'anoxic.' PHDs, then, are deprived of their cofactor, oxygen, and cannot hydroxylate $\mathrm{HIF}-\alpha$ protein to target it for degradation. ${ }^{50}$ Another model implicates ROS generation by the electron transport chain as a signaling molecule to HIF-1 $\alpha$ protein stabilization. ${ }^{51}$ Support for the ROS theory initially arose from the observation that, paradoxically, hypoxia increases ROS production, and treatment with antioxidants prevents $\mathrm{HIF}-1 \alpha$ protein stabilization. ${ }^{41}$ Additionally, exogenous $\mathrm{H}_{2} \mathrm{O}_{2}$ treatment stabilized HIF- $1 \alpha$ protein. ${ }^{41}$ Rho-zero cells are unable to generate ROS. Cells genetically depleted of cytochrome $c$ or the Rieske-Fe-S protein also fail to increase production of ROS during hypoxia. ${ }^{47,48}$ However, these studies did not conclusively identify the complex within the electron transport chain responsible for hypoxic ROS generation and HIF- $1 \alpha$ protein stabilization.

The $Q_{0}$ site complex III as part of oxygen sensing machinery. The pharmacologic and genetic data point to the ubiquinone $(\mathrm{Q})$ cycle of complex III as the source of ROS generation during hypoxia to stabilize HIF-1 $\alpha$ protein. ${ }^{41,43,47-49}$ Unlike complexes I and II, which generate superoxide into the mitochondrial matrix, ${ }^{52-55}$ complex III can also release superoxide into the mitochondrial intermembrane space and subsequently, into the cytosol. ${ }^{56-58}$ The $Q$ cycle is initiated when complex I and complex II transfer electrons to reduce the lipid moiety ubiquinone to ubiquinol (Figure 3). Ubiquinol then enters the $Q$ cycle (Figure 3 ). The first step in the $Q$ cycle is the transfer of electrons to the Rieske Fe-S protein, which oxidizes ubiquinol $\left(\mathrm{QH}_{2}\right)$ to ubisemiquinone $(\mathrm{QH} \bullet)$ at 
the Qo site of complex III. This electron is transferred to cytochrome $c_{1}$, which in turn reduces cytochrome $c$. Complex IV oxidizes cytochrome $c$ and then transfers the electron to molecular oxygen, reducing it to water. This pathway only accounts for one of the electrons that reduced ubiquinone to ubiquinol. At this point, the $Q$ cycle is only half complete because the other electron is still maintained by the highly reactive intermediate ubisemiquinone.

Ubisemiquinone quickly reduces the $b_{L}$ reaction center of cytochrome $b$ at the $Q_{0}$ site of Complex III. The electron is then passed from the $b_{L}$ reaction center to the $b_{H}$ reaction center of cytochrome $b$. The electron from the $b_{H}$ reaction center reduces either ubiquinone or ubisemiquinone at the $Q_{i}$ site of Complex III. When this electron is passed to the Rieske Fe-S protein and consequently cytochrome $c_{1}$ the $Q$ cycle is complete. Ubisemiquinone is a highly reactive intermediate that is generated at the $Q_{0}$ site. As a byproduct of electron transfer through the $Q$ cycle, ubisemiquinone can generate superoxide at the $Q_{0}$ site. Pharmacologic interventions indicate that $Q_{0}$ site is responsible for the generation of ROS during hypoxia. Stigmatellin, which inhibits electron flux to Rieske iron-sulfur protein, prevents ROS generation and HIF activation during hypoxia. ${ }^{48}$ In the absence of the Rieske Fe-S protein the $Q$ cycle is not initiated and there is no electron flow through complex III. By contrast, antimycin $A$ does not prevent the hypoxic increase in ROS production or HIF activation. ${ }^{41}$ Antimycin A prevents electron flux post cytochrome $b$. Thus, the $Q_{0}$ site is maintained while the $Q_{i}$ site is abolished.

Although the pharmacologic evidence indicates that the $Q_{0}$ site is a likely site of ROS generation during hypoxia, this needed to be validated with genetic interventions. The best method is to examine ROS production and HIF activation during hypoxia in cells deficient in cytochrome $b$, which will maintain a $Q_{o}$ site of ROS generation but not the $Q_{i}$ site. However, cytochrome $b$ gene is encoded my mtDNA and current siRNA techniques do not target mtDNA transcripts.

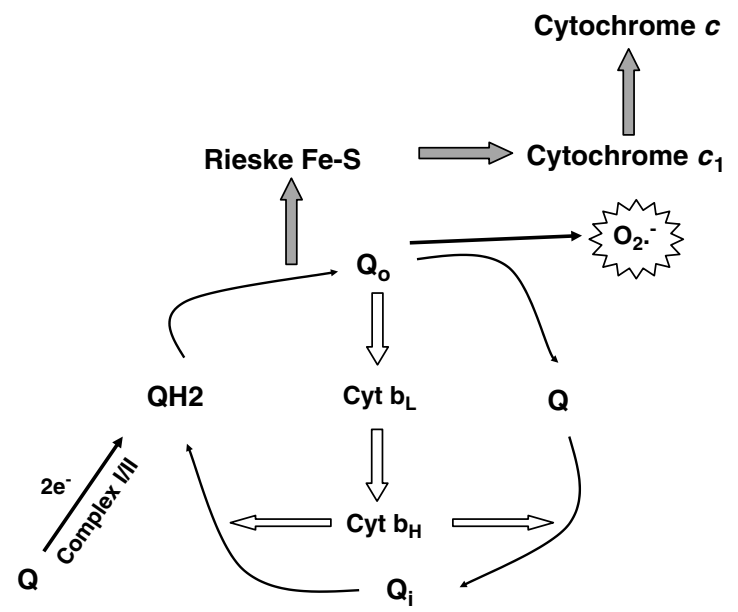

Figure 3 The ubiquinone $(Q)$ cycle is initiated when one electron from ubiquinol $\left(\mathrm{QH}_{2}\right)$ is donated to the Rieske-iron sulfur protein and the second electron is donated to cytochrome $b$. The intermediate moiety is the free radical ubisemiquinone $\left(Q_{0}\right)$, which can donate electrons to molecular oxygen to generate superoxide
Thus, we utilized cytochrome b mutant cybrids, generated by reconstituting 143B rho-zero cells with wild-type mitochondrial DNA or that containing a 4-bp deletion in the cytochrome b gene found in a patient suffering from parkinsonism. ${ }^{59}$ Loss of cytochrome $b$ renders these cells incapable of oxygen consumption and unable to generate ROS at the $Q_{i}$ site specifically. However, these cells were capable of upregulating hypoxic ROS and stabilizing HIF-1 $\alpha$ protein. ${ }^{60}$ The administration of the mitochondrial antioxidant MITOQ prevented the HIF-1 $\alpha$ protein stabilization. We also utilized RNAi to knock down Rieske Fe-S protein, to abolish ROS generation at the $Q_{0}$ site in mutant cytochrome $b$ cybrids. This prevented hypoxic ROS generation and HIF- $1 \alpha$ protein stabilization, implicating the $Q_{0}$ site of complex III as the key site in hypoxic ROS generation and HIF-1 $\alpha$ protein stabilization. These cells, however, retained the ability to stabilize HIF- $1 \alpha$ protein after direct PHD inhibition by dimethyloxallyl glycine, showing an otherwise intact HIF-signaling pathway. Furthermore, we established a link between hypoxic ROS generation and hydroxylation of HIF-1 $\alpha$ protein. Neutralizing the ROS with antioxidants allowed HIF- $1 \alpha$ protein to remain hydroxylated (and, therefore, primed for degradation) under hypoxic conditions. On the contrary, increasing ROS levels under normoxia by overexpressing glucose oxidase prevented normoxic $\mathrm{HIF}-1 \alpha$ protein hydroxylation. Importantly, these data demonstrate that the ROS generated by the mitochondria under hypoxia prevent hydroxylation of $\mathrm{HIF}-1 \alpha$ protein (Figure 4).

Our study is not compatible with the oxygen consumption model proposed by Hagen et al., ${ }^{50}$ which states that, as mitochondria consume oxygen under hypoxia, they leave the cytosol with insufficient oxygen for PHD function. Studies using rho-zero cells were unable to distinguish between oxygen consumption and mitochondrial ROS generation, as depleting mitochondrial DNA stops both of these functions. However, the cytochrome b cybrids are incapable of oxygen consumption while still able to generate ROS under hypoxia.

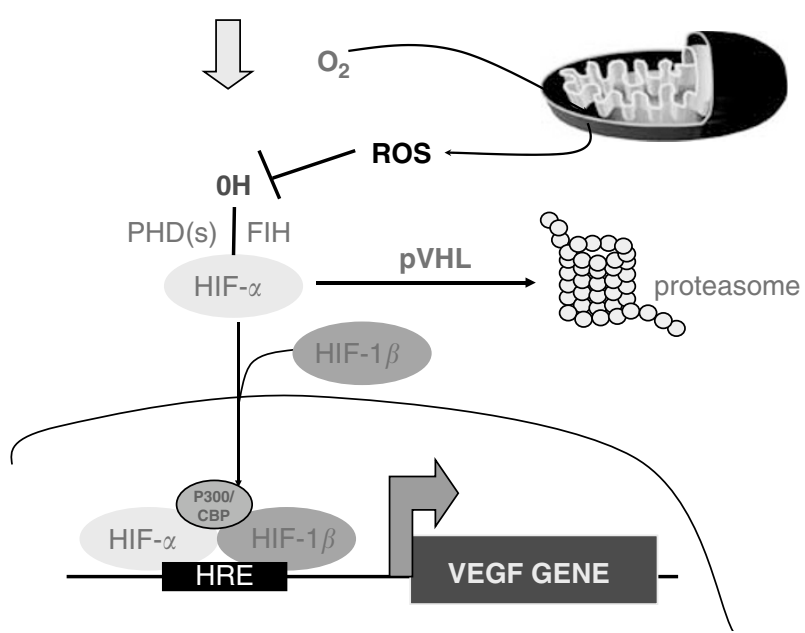

Figure 4 We propose that hypoxia increases the generation of reactive oxygen species that prevent hydroxylation of HIF- $\alpha$ protein, resulting in stabilization and activation of its transcriptional activity 


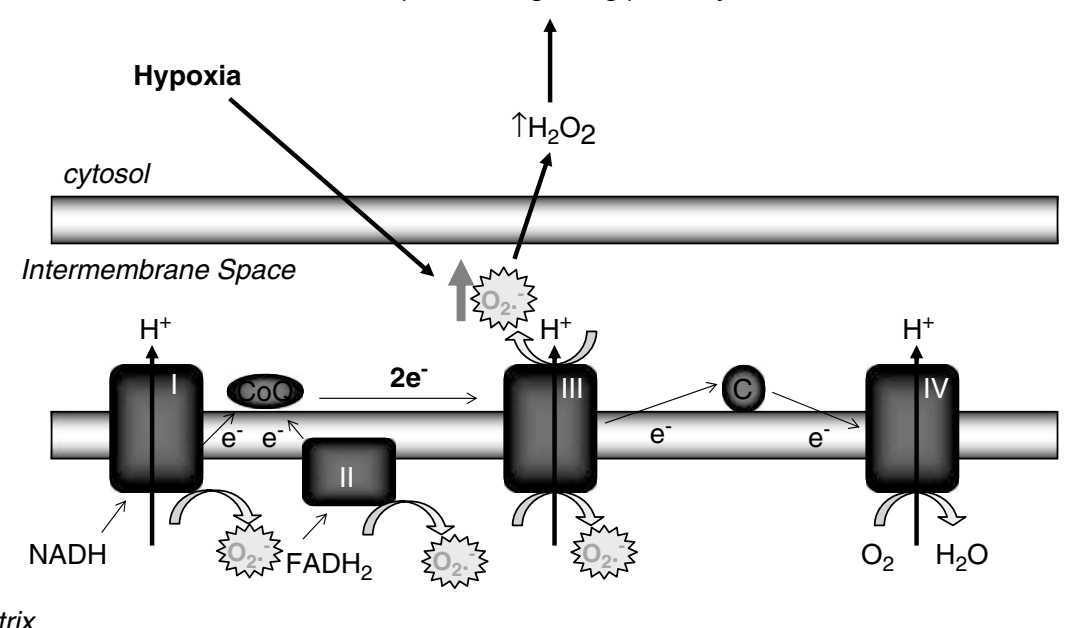

Figure 5 Mitochondrial electron transport chain generates superoxide at complex I, II, and III. Complex I and II generate superoxide within the mitochondrial matrix. Complex III can generate superoxide in both the intermembrane space and the matrix. We propose that complex III is an integral part of the oxygen-sensing machinery in mammalian cells. Hypoxia elicits the release of superoxide from complex III into the cytosol, where it is converted to $\mathrm{H}_{2} \mathrm{O}_{2}$ to activate oxidant-dependent signaling pathways resulting in the activation of HIF. Currently it is not known how hypoxia increases the release of ROS from complex III, or what oxidant-dependent signaling pathways are required for HIF activation

Unless these ROS are neutralized by antioxidants, HIF-1 $\alpha$ protein is stabilized in these cells under hypoxia. This indicates unequivocally that mitochondrial ROS generation, not oxygen consumption, contributes to HIF- $1 \alpha$ protein stabilization under hypoxia. In certain scenarios, however, a high rate of oxygen consumption by cells or cellular overcrowding under normal oxygen conditions can result in conditions close to anoxia. As the mitochondria utilize most of the oxygen, the cytosol may, indeed, be left anoxic, turning off PHDs ability to hydroxylate HIF- $1 \alpha$ protein. Overall, our recent study clearly implicates the $Q_{0}$ site of complex III as the source of ROS generation that prevents hydroxylation of the HIF- $1 \alpha$ protein to stabilize it under hypoxia.

\section{Mitochondrial ROS regulate HIF-dependent} tumorigenesis. While use of antioxidants has long been known to have anti-tumorigenic effects, the common assumption was that antioxidants prevented oncogenic lesions and genomic instability arising from ROS-induced DNA damage. To test whether antioxidants prevent tumorigenesis through attenuating HIF activation or genomic instability, Dang and colleagues ${ }^{61}$ tested efficacy of the antioxidant $N$-acetylcysteine (NAC) in human B cells that overexpress MYC in a xenograft model in SCID mice and transgenic mice that conditionally overexpress MYC in liver cells. Treatment of each kind of mouse with the antioxidant NAC reduced or prevented tumor growth. The human $B$ cells displayed no increase in genomic instability upon MYC induction, indicating that NAC was not preventing tumor growth by decreasing ROS-induced DNA damage. However, NAC treatment of these cells did suppress HIF- $1 \alpha$ protein stabilization under hypoxia. HIF- $1 \alpha$ protein mutants lacking oxygen-dependent degradation domains rescued tumor growth in the mice treated with NAC. Together, these data suggest that NAC acts on tumorigenesis by preventing HIF- $1 \alpha$ protein stabilization. This study provides a potential mechanistic relationship of why antioxidants might be effective as therapeutic potential for cancer prevention.

\section{Unanswered Questions}

Despite recent advances in our knowledge of HIF regulation by mitochondrial ROS, many questions remain unanswered. Particularly, how complex III increases the generation of superoxide to the intermembrane space and how mitochondrial superoxide that is converted to $\mathrm{H}_{2} \mathrm{O}_{2}$ signals to the $\mathrm{PHDs}$ remain unclear (Figure 5). An oxidant-dependent signaling pathway may lead to post-translational modification of PHDs, such as phosphorylation, which would render them inactive. $\mathrm{H}_{2} \mathrm{O}_{2}$ may also affect PHDs more directly. The PHDs are nonheme iron-dependent oxygenases that require $\mathrm{Fe}^{+2}$ for their enzymatic activity. $\mathrm{H}_{2} \mathrm{O}_{2}$ may cause a local Fenton reaction to shift iron ions from $\mathrm{Fe}^{+2}$ to $\mathrm{Fe}^{+3}$ causing inactivation of the enzyme. ${ }^{62}$

A combination of oxygen, iron, TCA cycle intermediate availability and ROS signaling might optimize the hydroxylation of $\mathrm{HIF} \alpha$ proteins. $^{63}$ Furthermore, recent studies have indicated that HIF-1 activation might prevent excessive ROS production in hypoxic cells by regulating mitochondrial respiration through increased gene expression of PDK1 (PDH (pyruvate dehydrogenase) kinase 1) and switching of cytochrome $c$ oxidase subunit IV isoforms. ${ }^{64-66}$ PDK1 
phosphorylates and inactivates $\mathrm{PDH}$, the mitochondrial enzyme that converts pyruvate into acetyl-CoA. PDK1 expression would shuttle pyruvate away from the generation of acetyl-CoA to lactate resulting in decreased substrate delivery to the tricarboxylic acid cycle. This would cause reduction in the levels of $\mathrm{NADH}$ and FADH2 delivered to the electron-transport chain, which could potentially decrease ROS generation. The switching of COX composition from increased expression of COX4-2 subunit and decreased in COX4-1 subunit makes the COX enzyme more efficient under hypoxic conditions. It is conceivable that an efficient COX would limit leak of electrons from the electron transport chain thereby diminishing the generation of ROS. Thus, it remains to be tested whether mitochondrial ROS would activate HIF-1, which as a feedback mechanism would decrease excessive ROS production through PDK1 and COX4-2 expression. Future studies are required to answer these questions. However, what is clear is that mitochondrial ROS generation is required for hypoxic stabilization of HIF- $1 \alpha$ protein, and that modulating mitochondrial ROS carries therapeutic implications in cancer and other HIF-dependent diseases.

Acknowledgements. This work is supported in part by National Institutes of Health Grants (GM60472-08 and CA123067-01) to NSC.

1. Semenza GL. HIF-1 and human disease: one highly involved factor. Genes Dev 2000; 14 1983-1991.

2. McClintock DS, Santore MT, Lee VY, Brunelle J, Budinger GR, Zong WX et al. Bcl-2 family members and functional electron transport chain regulate oxygen deprivation-induced cell death. Mol Cell Biol 2002; 22: 94-104.

3. Jones DP. Intracellular diffusion gradients of 02 and ATP. Am J Physiol 1986; 250: C663-C675.

4. Wilson DF, Rumsey WL, Green TJ, Vanderkooi JM. The oxygen dependence of mitochondrial oxidative phosphorylation measured by a new optical method for measuring oxygen concentration. J Biol Chem 1988; 263: 2712-2718.

5. Schroedl C, McClintock DS, Budinger GR, Chandel NS. Hypoxic but not anoxic stabilization of HIF-1alpha requires mitochondrial reactive oxygen species. Am J Physiol Lung Cell Mol Physiol 2002; 283: L922-L931.

6. Chandel NS, Vander Heiden MG, Thompson CB, Schumacker PT. Redox regulation of p53 during hypoxia. Oncogene 2000; 19: 3840-3848.

7. Semenza GL, Nejfelt MK, Chi SM, Antonarakis SE. Hypoxia-inducible nuclear factors bind to an enhancer element located $3^{\prime}$ to the human erythropoietin gene. Proc Natl Acad Sci USA 1991; 88: 5680-5684.

8. Semenza GL, Roth PH, Fang HM, Wang GL. Transcriptional regulation of genes encoding glycolytic enzymes by hypoxia-inducible factor 1. J Biol Chem 1994; 269: 23757-23763.

9. Semenza GL, Wang GL. A nuclear factor induced by hypoxia via de novo protein synthesis binds to the human erythropoietin gene enhancer at a site required for transcriptional activation. Mol Cell Biol 1992; 12: 5447-5454.

10. Hu CJ, Wang LY, Chodosh LA, Keith B, Simon MC. Differential roles of hypoxia-inducible factor 1alpha (HIF-1alpha) and HIF-2alpha in hypoxic gene regulation. Mol Cell Biol 2003 23: 9361-9374.

11. Tian H, McKnight SL, Russel DW. Endothelial PAS domainprotein 1 (EPAS1), a transcription factor selectively expressed in endothelial cells. Genes Dev 1997; 11 $72-82$.

12. Gu YZ, Moran SM, Hogenesch JB, Wartman L, Bradfield CA. Molecular characterization and chromosomal localization of a third alpha-class hypoxia inducible factor subunit, HIF3a. Gene Expr 1998; 7: 205-213.

13. Wang GL, Semenza GL. Purification and characterization of hypoxia-inducible factor 1 . J Biol Chem 1995; 270: 1230-1237.

14. Ebert BL, Bunn HF. Regulation of transcription by hypoxia requires a multiprotein complex that includes hypoxia-inducible factor 1 , an adjacent transcription factor, and p300/CREBbinding protein. Mol Cell Biol 1998; 18: 4089-4096.

15. Semenza GL. Perspectives on oxygen sensing. Cell 1999; 98: 281-284.

16. Semenza GL. Hypoxia-inducible factor 1: master regulator of $\mathrm{O}_{2}$ homeostasis. Curr Opin Genet Dev 1998; 8: 588-594.

17. Levy AP, Levy NS, Wegner S, Goldberg MA. Transcriptional regulation of the rat vascula endothelial growth factor gene by hypoxia. J Biol Chem 1995; 270: 13333-13340.
18. Forsythe JA, Jiang BH, lyer NV, Agani F, Leung SW, Koos RD et al. Activation of vascular endothelial growth factor gene transcription by hypoxia-inducible factor 1. Mol Cell Biol 1996; 16: 4604-4613.

19. Feldser D, Agani F, lyer NV, Pak B, Ferreira G, Semenza GL. Reciprocal positive regulation of hypoxia-inducible factor 1alpha and insulin-like growth factor 2. Cancer Res 1999; 59: 3915-3918.

20. Krishnamachary B, Berg-Dixon S, Kelly B, Agani F, Feldser D, Ferreira G et al. Regulation of colon carcinoma cell invasion by hypoxia-inducible factor 1. Cancer Res 2003; 63: 1138-1143.

21. Wang GL, Jiang BH, Rue EA, Semenza GL. Hypoxia-inducible factor 1 is a basic-helixloop-helix-PAS heterodimer regulated by cellular $\mathrm{O} 2$ tension. Proc Natl Acad Sci USA 1995; 92: 5510-5514.

22. Talks KL, Turley H, Gatter KC, Maxwell PH, Pugh CW, Ratcliffe PJ et al. The expression and distribution of the hypoxia-inducible factors HIF-1alpha and HIF-2alpha in normal human tissues, cancers, and tumor-associated macrophages. Am J Pathol 2000; 157: 411-421.

23. Sowter HM, Raval RR, Moore JW, Ratcliffe PJ, Harris AL. Predominant role of hypoxiainducible transcription factor (Hif)-1alpha versus Hif-2alpha in regulation of the transcriptional response to hypoxia. Cancer Res 2003; 63: 6130-6134.

24. Bruick RK, McKnight SL. A conserved family of prolyl-4-hydroxylases that modify HIF. Science 2001; 294: 1337-1340.

25. Epstein AC, Gleadle JM, McNeill LA, Hewitson KS, O'Rourke J, Mole DR et al. C elegans EGL-9 and mammalian homologs define a family of dioxygenases that regulate HIF by prolyl hydroxylation. Cell 2001; 107: 43-54.

26. Schofield CJ, Zhang Z. Structural and mechanistic studies on 2-oxoglutarate-dependent oxygenases and related enzymes. Curr Opin Struct Biol 1999; 9: 722-731.

27. Ivan M, Haberberger T, Gervasi DC, Michelson KS, Gunzler V, Kondo K et al. Biochemical purification and pharmacological inhibition of a mammalian prolyl hydroxylase acting on hypoxia-inducible factor. Proc Natl Acad Sci USA 2002; 99: 13459-13464.

28. Maxwell PH, Wiesener MS, Chang GW, Clifford SC, Vaux EC, Cockman ME et al. The tumour suppressor protein $\mathrm{VHL}$ targets hypoxia-inducible factors for oxygen-dependent proteolysis. Nature 1999; 399: 271-275.

29. Ivan M, Kondo K, Yang H, Kim W, Valiando J, Ohh M et al. 'HIF alpha targeted for VHL-mediated destruction by proline hydroxylation: implications for $\mathrm{O}_{2}$ sensing'. Science 2001; 292: 464-468.

30. Jaakkola P, Mole DR, Tian YM, Wilson MI, Gielbert J, Gaskell SJ et al. Targeting of HIF-alpha to the von Hippel-Lindau ubiquitylation complex by $\mathrm{O}_{2}$-regulated prolyl hydroxylation. Science 2001; 292: 468-472.

31. Kondo K, Klco J, Nakamura E, Lechpammer M, Kaelin Jr WG. Inhibition of HIF is necessary for tumor suppression by the von Hippel-Lindau protein. Cancer Cell 2002; 1: 237-246.

32. Maranchie JK, Vasselli JR, Riss J, Bonifacino JS, Linehan WM, Klausner RD. The contribution of VHL substrate binding and HIF1-alpha to the phenotype of VHL loss in renal cell carcinoma. Cancer Cell 2002; 1: 247-255.

33. Lando D, Peet DJ, Gorman JJ, Whelan DA, Whitelaw ML, Bruick RK. FIH-1 is an asparaginyl hydroxylase enzyme that regulates the transcriptional activity of hypoxia-inducible factor. Genes Dev 2002; 16: 1466-1471.

34. Lando D, Peet DJ, Whelan DA, Gorman JJ, Whitelaw ML. Asparagine hydroxylation of the HIF transactivation domain a hypoxic switch. Science 2002; 295: 858-861.

35. Mahon PC, Hirota K, Semenza GL. FIH-1: a novel protein that interacts with HIF-1alpha and VHL to mediate repression of HIF-1 transcriptional activity. Genes Dev 2001; 15: 2675-2686.

36. Dames SA, Martinez-Yamout M, De Guzman RN, Dyson HJ, Wright PE. Structural basis for HIF-1 alpha /CBP recognition in the cellular hypoxic response. Proc Natl Acad Sci USA 2002: 99: 5271-5276

37. Freedman SJ, Sun ZY, Poy F, Kung AL, Livingston DM, Wagner G et al. Structural basis for recruitment of CBP/p300 by hypoxia-inducible factor-1 alpha. Proc Natl Acad Sci USA 2002; 99: 5367-5372

38. Jiang BH, Semenza GL, Bauer C, Marti HH. Hypoxia-inducible factor 1 levels vary exponentially over a physiologically relevant range of $\mathrm{O}_{2}$ tension. Am J Physiol 1996; 271: C1172-C1180

39. Hirsila M, Koivunen P, Gunzler V, Kivirikko KI, Myllyharju J. Characterization of the human prolyl 4-hydroxylases that modify the hypoxia-inducible factor. J Biol Chem 2003; 278: 30772-30780.

40. Turrens JF. Mitochondrial formation of reactive oxygen species. J Physiol 2003; 552: 335-344.

41. Chandel NS, McClintock DS, Feliciano CE, Wood TM, Melendez JA, Rodriguez AM et al. Reactive oxygen species generated at mitochondrial complex III stabilize hypoxia-inducible factor-1alpha during hypoxia: a mechanism of $\mathrm{O}_{2}$ sensing. J Biol Chem 2000; 275: 25130-25138.

42. Agani FH, Pichiule P, Chavez JC, LaManna JC. The role of mitochondria in the regulation of hypoxia-inducible factor 1 expression during hypoxia. J Biol Chem 2000; 275 . 35863-35867.

43. Chandel NS, Maltepe E, Goldwasser E, Mathieu CE, Simon MC, Schumacker PT. Mitochondrial reactive oxygen species trigger hypoxia-induced transcription. Proc Nat Acad Sci USA 1998; 95: 11715-11720. 
44. DeHaan C, Habibi-Nazhad B, Yan E, Salloum N, Parliament M, Allalunis-Turner J. Mutation in mitochondrial complex I ND6 subunit is associated with defective response to hypoxia in human glioma cells. Mol Cancer 2004; 3: 19.

45. Chandel NS, Schumacker PT. Cells depleted of mitochondrial DNA (rho0) yield insight into physiological mechanisms. FEBS Lett 1999; 454: 173-176.

46. Vaux EC, Metzen E, Yeates KM, Ratcliffe PJ. Regulation of hypoxia-inducible factor is preserved in the absence of a functioning mitochondrial respiratory chain. Blood 2001; 98: 296-302.

47. Mansfield KD, Guzy RD, Pan Y, Young RM, Cash TP, Schumacker PT et al. Mitochondrial dysfunction resulting from loss of cytochrome $c$ impairs cellular oxygen sensing and hypoxic HIF-alpha activation. Cell Metab 2005; 1: 393-399.

48. Guzy RD, Hoyos B, Robin E, Chen H, Liu L, Mansfield KD et al. Mitochondrial complex III is required for hypoxia-induced ROS production and cellular oxygen sensing. Cell Metab 2005; 1: 401-408.

49. Brunelle JK, Bell EL, Quesada NM, Vercauteren K, Tiranti V, Zeviani M et al. Oxygen sensing requires mitochondrial ROS but not oxidative phosphorylation. Cell Metab 2005; 1 : 409-414.

50. Hagen T, Taylor CT, Lam F, Moncada S. Redistribution of intracellular oxygen in hypoxia by nitric oxide: effect on HIF1alpha. Science 2003; 302: 1975-1978.

51. Bell EL, Emerling BM, Chandel NS. Mitochondrial regulation of oxygen sensing. Mitochondrion 2005; 5: 322-332.

52. Turrens JF, Boveris A. Generation of superoxide anion by the NADH dehydrogenase of bovine heart mitochondria. Biochem J 1980; 191: 421-427.

53. Genova ML, Ventura B, Giuliano G, Bovina C, Formiggini G, Parenti Castelli G et al. The site of production of superoxide radical in mitochondrial complex I is not a bound ubisemiquinone but presumably iron-sulfur cluster N2. FEBS Lett 2001; 505: 364-368.

54. Zhang L, Yu L, Yu CA. Generation of superoxide anion by succinate-cytochrome $c$ reductase from bovine heart mitochondria. J Biol Chem 1998; 273: 33972-33976.

55. Paddenberg R, Ishaq B, Goldenberg A, Faulhammer P, Rose F, Weissmann N et al. Essential role of complex II of the respiratory chain in hypoxia-induced ROS generation in the pulmonary vasculature. Am J Physiol Lung Cell Mol Physiol 2003; 284: L710-L719.
56. Boveris A, Cadenas E, Stoppani AO. Role of ubiquinone in the mitochondrial generation of hydrogen peroxide. Biochem J 1976; 156: 435-444.

57. Turrens JF, Alexandre A, Lehninger AL. Ubisemiquinone is the electron donor for superoxide formation by complex III of heart mitochondria. Arch Biochem Biophys 1985; 237: 408-414.

58. Muller FL, Liu Y, Van Remmen H. Complex III releases superoxide to both sides of the inner mitochondrial membrane. J Biol Chem 2004; 279: 49064-49073.

59. Rana M, de Coo I, Diaz F, Smeets H, Moraes CT. An out-of-frame cytochrome b gene deletion from a patient with parkinsonism is associated with impaired complex II assembly and an increase in free radical production. Ann Neurol 2000; 48: 774-781.

60. Bell EL, Klimova TA, Eisenbart J, Moraes CT, Murphy MP, Budinger GR et al. The $Q_{0}$ site of the mitochondrial complex III is required for the transduction of hypoxic signaling via reactive oxygen species production. J Cell Biol 2007; 177: 1029-1036.

61. Gao P, Zhang H, Dinavahi R, Li F, Xiang Y, Raman V et al. HIF-dependent antitumorigenic effect of antioxidants in vivo. Cancer Cell 2007; 12: 230-238.

62. Gerald D, Berra E, Frapart YM, Chan DA, Giaccia AJ, Mansuy D et al. JunD reduces tumor angiogenesis by protecting cells from oxidative stress. Cell 2004; 118: 781-794.

63. Pan Y, Mansfield KD, Bertozzi CC, Rudenko V, Chan DA, Giaccia AJ et al. Multiple factors affecting cellular redox status and energy metabolism modulate hypoxia-inducible factor prolyl hydroxylase activity in vivo and in vitro. Mol Cell Biol 2007; 27: 912-925.

64. Kim JW, Tchernyshyov I, Semenza GL, Dang CV. HIF-1-mediated expression of pyruvate dehydrogenase kinase: a metabolic switch required for cellular adaptation to hypoxia. Cell Metab 2006; 3: 177-185.

65. Papandreou I, Cairns RA, Fontana L, Lim AL, Denko NC. HIF-1 mediates adaptation to hypoxia by actively downregulating mitochondrial oxygen consumption. Cell Metab 2006 3: 187-197.

66. Fukuda R, Zhang H, Kim J-W, Shimoda L, Dang CV, Semenza GL. HIF-1 regulates cytochrome oxidase subunits to optimize efficiency of respiration in hypoxic cells. Cell 2007; 129: 111-122. 